\title{
PERAHU FIBERGLASS UNTUK PENUNJANG ALAT PENANGKAP IKAN DAN SEKTOR PARIWISATA DESA SUMBERASRI KECAMATAN PURWOHARJO BANYUWANGI
}

\author{
Setyo Pambudi'), Mochamad Asrofi'1), Agus Triono'), Mumtadz Zaid Bin Tsabit'1), \\ Nizam Alfi Murtadho') \\ 1)Jurusan Teknik Industri, Fakultas Teknik, Institut Teknologi dan Bisnis Muhammadiyah Banyuwangi, Banyuwangi, \\ Jawa Timur, Indonesia \\ Corresponding author : Mochamad Asrofi \\ E-mail : setyopmbd@gmail.com
}

Diterima 09 Juli 2021, Direvisi 29 Juli 2021, Disetujui 29 Juli 2021

\begin{abstract}
ABSTRAK
Fiberglass lebih ekonomis dibandingkan dengan kayu maupun logam untuk bahan pembuatan kapal yang berukuran kecil. Kegiatan pengabdian kepada masyarakat ini bertujuan untuk memberikan pengetahuan tentang design kapal dan bahan pembuatan kapal berupa Fiberglass Reinforced Plastics (FRP). Pengetahuan tentang design kapal, dan pengetahuan bahan Fiberglass Reinforced Plastics (FRP) dianggap penting karena masih kurangnya pengetahuan akan hal tersebut. Pembuatan kapal berbahan fiberglass secara tidak tepat dapat mengakibatkan pengendalian kapal yang kurang maksimal. Selain itu, kekuatan lambung kapal juga tidak sesuai dengan standard. Kegiatan pengabdian ini dilakukan dengan dua tahap yaitu pelatihan dan pendampingan pembuatan kapal berbahan fiberglass. Dari hasil evaluasi didapatkan bahwa peserta memiliki keterampilan teknik hand lay-up dan pengetahuan bahan yang baik setelah diadakannya pelatihan dan pendampingan.
\end{abstract}

Kata kunci: kapal; fiberglass; hand lay-up; nelayan; pariwisata; mangrove

\begin{abstract}
Fiberglass is more economical than wood or metal for small shipbuilding materials. This community service activity aims to provide knowledge about ship design and shipbuilding materials in the form of Fiberglass Reinforced Plastics (FRP). Knowledge of ship design, and knowledge of Fiberglass Reinforced Plastics (FRP) is considered important because there is still a lack of knowledge about it. Making boats made of Fiberglass improperly can result in less than optimal ship control. In addition, the hull of the ship is also not up to standard. This service activity is carried out in two stages, namely training and mentoring in the manufacture of Fiberglass boats. From the evaluation results, it was found that of the participants had good hand lay-up technique skills and material knowledge after the training and mentoring.
\end{abstract}

Keywords: boat; fiberglass; hand lay-up; fisherman; tourism; mangrove

\section{PENDAHULUAN}

Usaha perikanan laut di Indonesia 95\% merupakan usaha skala kecil atau usaha perikanan tadisional. Wilayah desa Sumberasri memiliki topografi dataran rendah dengan ketinggian tanah dari permukaan laut sebesar 0-32 mdpl. Desa Sumberasri memiiki potensi ekowisata mangrove blok bedul. Blok bedul memiliki luas $30 \mathrm{Ha}$ yang merupakan zona pernapasan. Ekowisata mangrove blok bedul memiliki keanekaragaman flora dan fauna serta keindahan pantai selatan jawa (Dahniar, 2020). Surplus konsumen ekowisata mangrove blok bedul pada tahun 2009 menghasilkan total valuasi ekonomi adalah Rp. 88.606.183,00untuk kunjungan per 1000 orang pertahun (Saifullah \& Harahap, 2013). Kapal dibutuhkan untuk alat transportasi ekowisata mangrove blok bedul dan alat penangkap ikan bagi nelayan wilayah desa Sumberasri.

Kapal penangkap ikan tradisional $90 \%$ beroperasi di wilayah pantai (Manas et al., 2015). Kapal berbahan fiberglass memiliki peran penting di dalam menunjang transportasi laut nasional khususnya di wilayah pantai. Kapal berbahan fiberglass memiliki beberapa keunggulan teknis dan ekonomis (Ma'ruf \& Jamaluddin, 2010). Selain itu, pembuatan kapal bebahan fiberglass dinilai lebih menguntungkan dikarenakan kebutuhan utama maupun pendukung pembuatan kapal berbahan fiberglass lebih mudah didapatkan. Dibandingkan dengan kapal berbahan kayu atau logam, kapal berbahan fiberglass dinilai 
lebih ekonomis untuk kapal-kapal yang berukuran kecil (Ariesta et al., 2018). fiberglass diharapkan dapat menggantikan kayu sebagai bahan utama pembuatan kapal terutama kapal yang berukuran kecil (Fuadi et al, 2010.). Fiberglass atau Fiberglass Reinforced Plastics (FRP) adalah sejenis material komposit struktur dengan resin sintetis sebagai matriks dan serat sebagai kerangka (Chen, 2020). Metode hand lay-up adalah metode yang paling sederhana untuk pengolahan komposit. Meskipun sifat mekanis yang dihasilkan tidak sebaik metode vacuum infusion, dan vacuum bagging, namun peralatan yang digunakan untuk metode hand lay-up tergolong sederhana (Abdurohman et al., 2018).

Permasalahan yang dialami oleh nelayan yang menggunakan kapal berbahan fiberglass adalah design dari kapal yang akan dibuat. Kapal berbahan fiberglass memiliki kekurangan ketika mengalami kecelakaan (terbalik) akan langsung tenggelam. Selain itu, kapal berbahan fiberglass lebih sulit dikendalikan dibandingkan dengan kapal berbahan kayu. Kapal berbahan fiberglass memiliki stabilitas yang rendah. Fiberglass memiliki bobot yang ringan membuat kapal mudah oleng meskipun dioprasikan pada perairan yang relatif tenang (Thahir, 2018).

Kegiatan pengabdian kepada masyarakat yang dilakukan didesa Sumberasri bertujuan unuk memberikan pengetahuan kepada

\section{METODE}

Kegiatan pengabdian kepada masyarakat (PKM) dilakukan di desa Sumberasri kecamatan Purwoharjo kabupaten Banyuwangi. Mitra dalam kegiatan PKM ini adalah kelompok nelayan kelompok usaha Bersama (KUB) Baruna Jaya yang berjumlah 10 orang. Tim pelaksana terdiri dari ketua LPPM ITBM Banyuwangi, Kaprodi Teknik industri, beserta tenaga pengajar jurusan Teknik Industri ITBM Banyuwangi. Kegiatan PKM ini diakukan guna memberikan materi secara teoritis dan praktik sehingga proses pembuatan kapal berbahan FRP sesuai dengan standard. Tahapan yang dilakukan dalam kegiatan PKM ini antara lain:

1. Pengurusan izin pelaksanaan kegiatan PKM kepada kepala desa Sumberasri.

2. Pembuatan design kapal oleh tim pelaksana

3. Sosialisasi design kapal berbahan Fiberglass Reinforced Plastic (FRP)
4. Praktik pembuatan kapal berbahan Fiberglass Reinforced Plastic (FRP)

5. Evaluasi kegiatan PKM yang telah dilakukan.

\section{Design Kapal}

Kapal ikan ini dibangun menggunakan bahan Fiberglass Reinforced Plastic (FRP) berbasis Komposit dengan teknik hand lay-up atau laminasi. Bahan komposit mempunyai keunggulan di antaranya densitas (massa jenis) ringan dan mempunyai sifat mekanik yang baik. Kapal ini digerakkan oleh satu unit mesin penggerak (motor) tempel / outboard berbalingbaling.

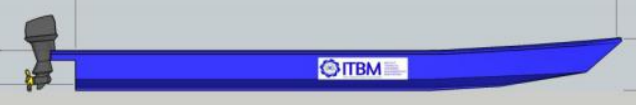

Gambar 1. Design kapal berbahan fiberglass

Kapal didesain dengan tambahan kantong udara pada bagian depan kapal (ruang ceruk). Ruang ceruk merupakan ruang kosong dan kedap. Hal ini dimaksudkan agar kapal tidak langsung tenggelam ketika mengalami kecelakaan. Selain itu, kapal didesain memiliki lunas (keel) pada bagian bawah. Hal ini dimaksudkan agar pengendalian kapal semakin mudah. Lunas diharapkan dapat meningkatkan stabilitas dari kapal, dan mampu mengurangi gerakan rolling pada kapal (Thahir, 2018).

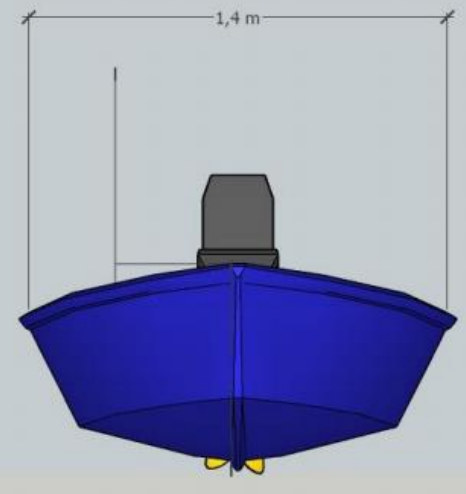

Gambar 2. Tampak depan kapal (lunas kapal)

\section{Alat dan Bahan Pembuatan Kapal}

Fiberglass atau Fiberglass Reinforced Plastics (FRP) adalah produk yang terdiri dari resin, bahan penguat fiberglass (roving mat) dan bahan tambahan katalis yang digabung dan diproses agar didapat kinerja yang spesifik sesuai kebutuhan (Yusuf, 2020). Resin merupakan material cair sebagai pengikat serat penguat yang memiliki kekuataan tarik serta 
kekakuan lebih rendah dibandingkan serat penguatnya.

Laminasi Chopped Strand Mat (CSM) ini digunakan sebagai lapisan pengikat antara supaya tidak mudah terkelupas maupun selip pada proses laminasi berikutnya juga sering dipakai sebagai laminasi awal dan akhir dengan tujuan bagian sisi tersebut menjadi rata. Woven roving adalah serat penguat berupa filament yang berbentuk anyaman plat yang saling tegak lurus antara lusi dan pakannya. Woven roving dipakai sebagai laminasi utama akan menambah kekuatan tarik dan lengkung yang lebih tinggi daripada laminasi Mat. Woven cloth adalah kain yang berasal dari serat gelas yang dipintal menjadi benang kemudian benangbenang itu ditenun menjadi kain. Woven cloth akan menambah ketebalan plat dan lebih ekonomis jika digunakan tersendiri (Sulasminingsih et al., 2017).

Bahan utama pembuatan kapal tersebut dari FRP (Fibreglass Reinforced Plastic) diperkuat dengan penguat-penguat membujur dan melintang yang terbuat dari balok-balok / frame fibreglass dengan isi foam dengan density $60 \mathrm{~kg} / \mathrm{m} 3$. Material fiberglass yang digunakan untuk kontruksi harus memiliki kekuatan uji tarik minimum $85 \mathrm{MPa}$. Seluruh bagian kapal mempunyai 6 lapisan (layer). Adapun bahan bahan yang digunakan ditampilkan dalam tabel 1.

Tabel 1 Bahan pembuatan kapal

\begin{tabular}{|c|c|c|}
\hline No & Nama Bahan & Bagian Kontruksi \\
\hline 1 & Resin Epoxy & Semua bagian kapal \\
\hline 2 & $\begin{array}{l}\text { Katalis } \\
\text { (hardener) }\end{array}$ & Semua bagian kapal \\
\hline 3 & $\begin{array}{l}\text { Serat halus } \\
\text { (roving mat) }\end{array}$ & Semua bagian kapal \\
\hline 3 & $\begin{array}{l}\text { Serat kasar } \\
\text { (woven roving) }\end{array}$ & Semua bagian kapal \\
\hline 4 & $\begin{array}{l}\text { Tepung } \\
\text { Aerosil } \\
\text { Pewarna }\end{array}$ & Campuran Pigment \\
\hline 5 & $\begin{array}{l}\text { Pigmen } \\
\text { Orange dan } \\
\text { putih }\end{array}$ & Lambung kapal \\
\hline 6 & Mirror glaze & Pelapisan mold \\
\hline 7 & Dempul & Cetakan lambung kapa \\
\hline 8 & Kobalt blue & Campuran Gelcoat \\
\hline 9 & Foam & Gading kapal \\
\hline 10 & Gelcoat & Lapisan dasar \\
\hline
\end{tabular}

\section{Langkah Pembuatan Kapal}

Adapun langkah-langkah pembuatan kapal antara lain:

1. Mempersiapkan cetakan kapal (mould). Cetakan kapal dibersihkan dari berbagai kotoran dan dilapisi dengan mirror glaze;
2. Pengecatan dengan menggunakan gelcoat sebagai lapisan dasar kapal;

3. Proses pembuatan lambung kapal yang tediri dari 6 lapis dengan metode hand lay-up;

4. Pembuatan gading kapal dengan menggunakan foam yang dilapisi dengan resin dan kobalt blue;

5. Pelepasan lambung kapal dari cetakan setelah semua bagian dari kapal kering.

\section{HASIL DAN PEMBAHASAN}

Kegiatan pengabdian kepada masyarakat KUB. Baruna jaya desa Sumberasri melalui pelatihan dan pendampingan pembuatan kapal berbahan fiberglass dengan beberapa pelaksanaan antara lain:

\section{Pelatihan}

Kegiatan awal yang dilakukan adalah pelatihan. Pelatihan dimaksudkan untuk memberikan transfer teknologi pembuatan kapal berbahan fiberglass yang telah didesain sebelumnya. Materi yang disampaikan dapat membuka wawasan tentang design kapal dan bagian-bagian kapal, pengenalan Fiberglass Reinforced Plastics (FRP), komposisi bahan baku yang digunakan, dan metode pembuatan kapal dengan metode hand lay-up.

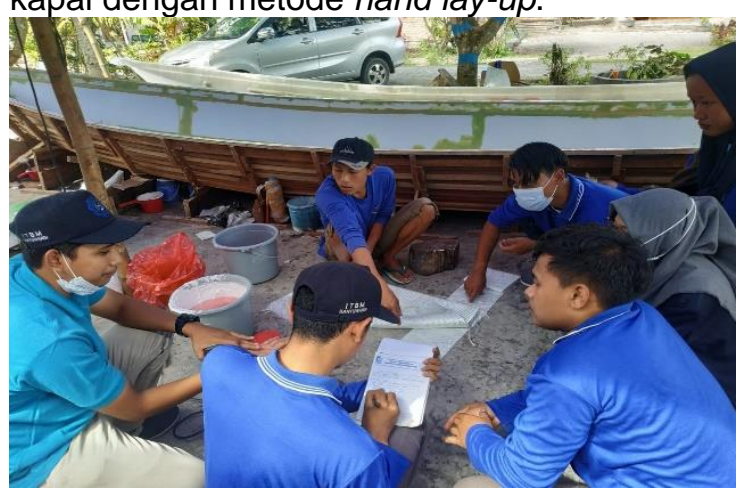

Gambar 3. Kegiatan penyampaian materi pembuatan perahu Fiberglass

Penyampaian materi dilakukan langsung di lapangan beserta praktik pembuatan kapal. Hal ini dimaksudkan agar materi dapat diterima dengan baik. Praktik pembuatan kapal juga dilakukan. Pembuatan kapal dilakukan secara langsung yang melibatkan kelompok nelayan KUB. Baruna jaya dan mahasiswa Institut Teknologi dan Bisnis Muhammadiyah Banyuwangi. 


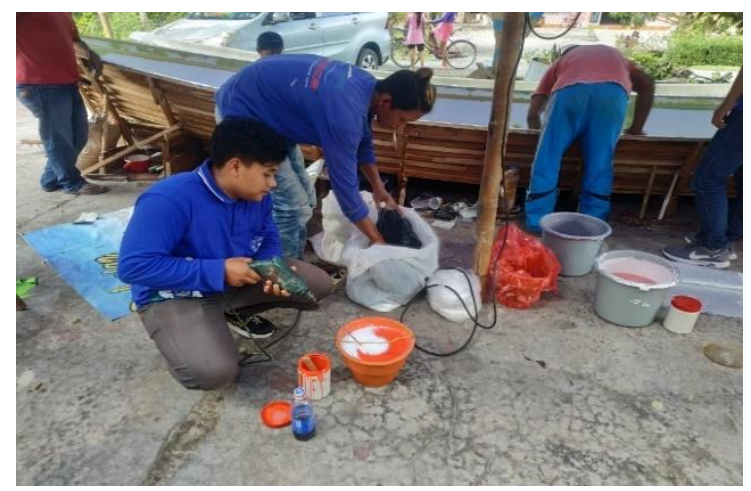

Gambar 4. Kegitan persiapan pembuatan perahu fiberglass

\section{Pendampingan}

Kegiatan kedua dilakukan pendampingan. Pendampingan dilakukan secara langsung pada saat pembuatan kapal. Kegiatan pendampingan yang dilakukan antara lain pelapisan mould dengan mirror glaze, pelapisan dengan menggunakan gelcoat, pembuatan lambung kapal dengan metode hand lay-up sampai dengan pelepasan kapal dari cetakan (mold). Selain itu tahap finishing pengecatan dan pemasangan stiker juga dilakukan.

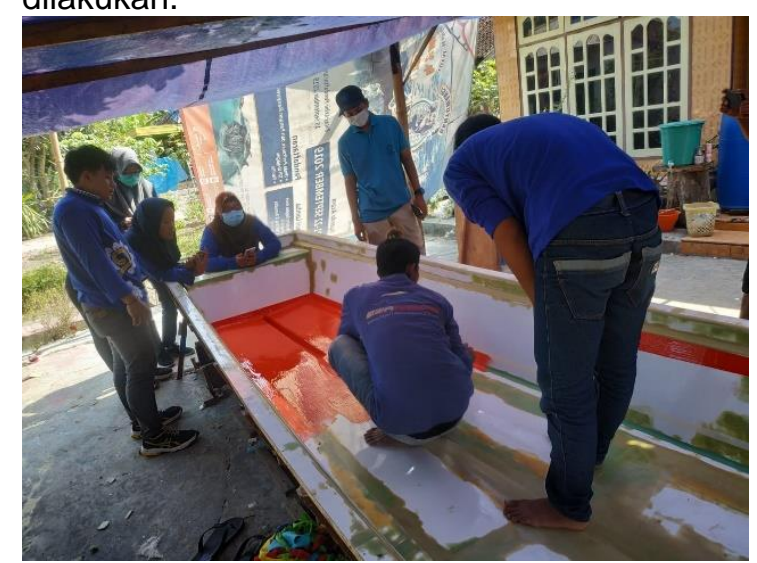

Gambar 5. Pelapisan cetakan (mold) dengan menggunakan mirror glaze

\section{Evaluasi}

Kegiatan akhir dari kegiatan pengabdian ini adalah evaluasi. Evaluasi dilakukan guna melihat pencapaian akhir dari kegiatan pembuatan kapal. Antusiasme peserta dan hasil akhir pembuatan kapal adalah bahan pertimbangan dari evaluasi. Pembuatan kapal yang dilakukan juga menunjukkan hasil yang baik. Pembuatan kapal berbahan fiberglass dibutuhkan pengetahuan tentang design dan bahan yang digunakan yaitu Fiberglass Reinforced Plastics (FRP).

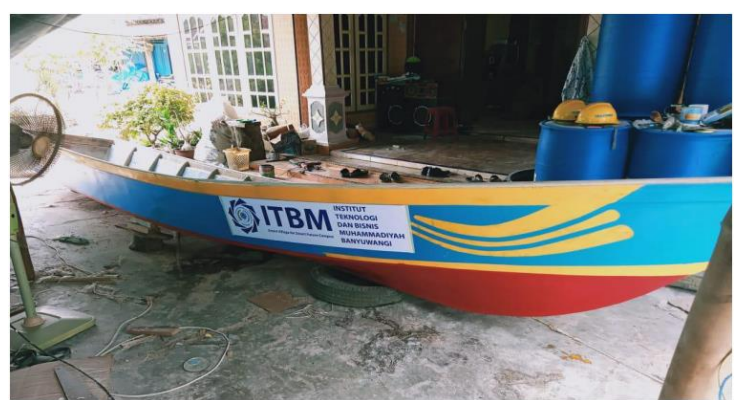

Gambar 1. Hasil pembuatan kapal berbahan Fiberglass Reinforced Plastics (FRP),

Selain itu keterampilan peserta dalam teknik atau metode hand lay-up juga menentukan hasil akhir pembuatan kapal berbahan Fiberglass Reinforced Plastics (FRP)

\section{SIMPULAN DAN SARAN}

Kegiatan pengabdian kepada masyarakat berupa pembuatan kapal berbahan Fiberglass Reinforced Plastics (FRP) ini mendapatkan antusiasme peserta yang besar. Kegiatan pelatihan dan pendampingan ini bermanfaat untuk memberikan pengetahuan tentang design dan Fiberglass Reinforced Plastics (FRP). Kegiatan pengabdian kepada masyarakat di desa Sumberasri ini berhasil mencapai target yang diharapkan. Pembuatan kapal berbahan Fiberglass Reinforced Plastics (FRP) telah tercapai dan mendapatkan hasil yang maksimal. Dihrapkan bahwa peserta pelatihan dapat menularan pengetahuan dan keterampilan terhadap nelayan yang lain yang berada di sekitar lokasi pelatihan. Diharapkan juga bahwa perawatan kapal berbahan fiberglass dilakukan dengan baik untuk memperpanjang masa pakai kapal.

\section{UCAPAN TERIMAKASIH}

Ucapan terima kasih ditujukan kepada kepala desa Sumberasri beserta kelompok usaha bersama Baruna Jaya atas terselenggaranya pelatihan dan pendampingan pembuatan kapal berbahan Fiberglass Reinforced Plastics (FRP).

\section{DAFTAR RUJUKAN}

Abdurohman, K., Satrio, T., Muzayadah, N. L., \& Teten. (2018). A comparison process between hand lay-up, vacuum infusion and vacuum bagging method toward eglass EW 185/lycal composites. Journal of Physics: Conference Series, 1130(1). https://doi.org/10.1088/17426596/1130/1/012018

Ariesta, R. C., Arif, M. S., \& Puspitasari, H. P. (2018). Comparison of Economical Analysis of Wood And Fiberglass Vessels In Randuboto Village, Gresik Regency, East Java. Economic and Social Fisheries 
and Marine, 006(01), 73-82. https://doi.org/10.21776/ub.ecsofim.2018. 006.01 .07

Chen, L. sheng. (2020). Discussion on the application of fiberglass reinforced plastics in building energy saving. IOP Conference Series: Earth and Environmental Science, 580(1). https://doi.org/10.1088/1755$1315 / 580 / 1 / 012051$

Dahniar, B. enmajita. (2020). Faktor-faktor yang menyebabkan menurunnya jumlah wisatawan di ekowisata mangrove blok bedul taman nasional alas purwo Banyuwangi. Skripsi.

Ma'ruf, B., \& Jamaluddin, A. (2010). Teknologi Pembangunan Skala Komersil Kapal SepHull Berbahan Fiberglass. Majalah Pengkajian Industri, 113-122. https://www.researchgate.net/profile/Bua na_Maruf/publication/325270131_TEKN OLOGI_PEMBANGUNAN_SKALA_KOM ERSIL_KAPAL_SEP.

HULL_BERBAHAN_FIBERGLASS/links/ 5b02ca580f7e9be94bda9d13/TEKNOLO GI-PEMBANGUNAN-SKALA-

KOMERSIL-KAPAL-SEP-HULLBERBAHAN-FIBERGLASS.pdf

Manas, A., Masengi, K. W. A., \& Kumajas, H. J. (2015). Studi tentang olengan bebas dan tahanan total kapal model uji di Laboratorium Kepelautan. Jurnal IImu Dan Teknologi Perikanan Tangkap, 2, 3338.

https://doi.org/10.35800/jitpt.2.0.2015.699 3

Pembahasan, H. D. A. N. (n.d.). KAJIAN DESAIN DAN KONSTRUKSI PERAHU FIBERGLASS REINFORCED PLASTIC PANJANG 9 METER DI CILACAP UTARA. $D$.

Saifullah, \& Harahap, N. (2013). Strategis Pengembangan Wisata Mangrove di "Blok Bedul"Taman Nasional Alas Purwo Kabupaten Banyuwangi Jawa Timur. Jurnal of Indonesian Tourism and Development Studies, 1(2), 79-86.

Sulasminingsih, S., Setyawan, B. A., \& Marasabessy, A. (2017). Studi ekonomi teknik pembuatan perahu cadik jenis bottom glass dari bahan fiber glass untuk wisata bahari di kelurahan banten kecamatan kasemen kota serang provinsi banten. Bina Teknika, 13(2), 205-213. https://ejournal.upnvj.ac.id/index.php/Bin aTeknika/article/view/1324

Thahir, M. A. (2018). Stabilitas Sampan Dengan Bilge Keel Pada Sudut 30 Dan 60 Derajat. Jurnal Perikanan Tropis, 5(2), 139. https://doi.org/10.35308/jpt.v5i2.1033

Yusuf, Z. (2020). Pelatihan Reparasi Perahu
Fiberglass bagi Nelayan Kabupaten Takalar. JURNAL TEPAT: Applied Technology Journal for Community Engagement and Services, 3(2), 42-48. https://doi.org/10.25042/jurnal_tepat.v3i2. 135 